\title{
Long-term results of the management of silicone oil-induced raised intraocular pressure by diode laser cycloablation
}

SMS Ghazi-Nouri, AN Vakalis, PA Bloom, C Bunce and DG Charteris
Abstract

Aims/background To analyse the effectiveness and safety of cyclodiode treatment in eyes with silicone oil-related raised intraocular pressure (IOP) and to correlate the results with clinical features of treated eyes.

Methods Retrospective review of case notes of all eyes that underwent cyclodiode treatment following injection of silicone oil at Moorfields Eye Hospital between April 1993 and January 2003 and were followed up for at least 1 year.

Results In all, 38 patients were followed up for between 13 and 113 months. Totally, 17 had silicone oil in situ at the time of first treatment. The mean pretreatment IOP was $31.4 \mathrm{mmHg}$ (SD 10.9), reducing to $18.6 \mathrm{mmHg}$ (SD 8.6) at 1 year and to $13.9 \mathrm{mmHg}$ (SD 8.4) at the final follow-up visit $(P<0.001)$. Before treatment, $28(73.7 \%)$ patients were on two or more topical medications. This was reduced to $18(47.4 \%)$ patients $(P=0.013)$ at 1 year and 13 (34.2\%) patients $(P=0.0007)$ at final follow-up. Use of oral acetazolamide for glaucoma was reduced from $16(42.1 \%)$ patients precyclodiode to five $(13.2 \%)$ patients at 1 year $(P=0.0034)$ and three $(7.9 \%)$ patients at the final visit $(P=0.001)$. Four patients $(10.5 \%)$ at 1 year and five patients $(13.2 \%)$ at the final visit had hypotony (defined as IOP of less than $5 \mathrm{mmHg}$ ). One patient had enucleation 75 months following first cyclodiode treatment.

Conclusion Diode laser photocoagulation can successfully control silicone oil-induced raised intraocular pressure where medical treatment fails. Reduction of IOP appears to be maintained long term.
Eye (2005) 19, 765-769. doi:10.1038/sj.eye.6701648; published online 10 September 2004

Keywords: cyclodiode; silicone oil; glaucoma

\section{Introduction}

Silicone oil is a valuable tool in the management of various forms of complex vitreoretinal disease. Raised intraocular pressure (IOP) remains, however, a significant complication of intraocular silicone oil with reported incidences of between 5.9 and $48 \%$ of eyes. ${ }^{1-5}$ When topical medication fails to control the IOP these eyes present a challenging management problem. Silicone oil removal may result in pressure control although recent reports indicate that additional antiglaucomatous medication will still be necessary in many eyes ${ }^{3,4}$ and that even with such additional medication over $50 \%$ of eyes will have uncontrolled intraocular pressure. ${ }^{3,6}$ Furthermore, removal of silicone oil may be contraindicated in eyes where there is a perceived high risk of retinal redetachment or postoperative hypotony. ${ }^{1}$

Reduction of aqueous production by ciliary body destruction is a potential method of IOP control. Cyclocryotherapy, while often effective in pressure reduction, is commonly associated with marked intraocular inflammation and is difficult to titrate with a high incidence of subsequent hypotony. ${ }^{7}$ Cyclodiode laser cyclodestruction offers a more controlled method of pressure reduction. This report documents the long-term follow-up (13-113 months, median 68 months) of 38 eyes which underwent trans-scleral diode laser ciliary body destruction to control raised IOP associated with intraocular silicone oil.
Vitreoretinal Research Department Moorfields Eye Hospital City Road, London, UK

Correspondence: SMS Ghazi-Nouri Vitreoretinal Research Unit Moorfields Eye Hospital City Road

London EC1V 2PD, UK

Tel: +44 2075662283

Fax: + 442075662285

E-mail: snouri@

doctors.org.uk

Received: 18 December 2003

Accepted: 1 June 2004

Published online:

10 September 2004 


\section{Patients and methods}

Using a computerised database patients were identified who had undergone cycloablation by diode laser at Moorfields Eye Hospital during the period 1993-2000 and were followed up till January 2003. In total, 41 patients were identified all of whom had adequate data for retrospective analysis. Three patients who had less than 12 months follow-up were excluded and the remaining 38 records were analysed further.

Data were recorded retrospectively from case notes and included primary vitreoretinal diagnosis, number and type of vitreoretinal procedures, previous ophthalmic history, lens status, and topical and systemic medications used to control IOP. The number of cyclodiode treatments together with laser power, duration, and number of pulses were documented. IOP was recorded prior to cyclodiode, 1 day postlaser and at 12 months and final follow-up visit. Statistical analysis was carried out using paired $t$ - and McNemar's tests. Raised IOP was defined as IOP greater than $21 \mathrm{mmHg}$.

\section{Results}

In all, 38 patients in total were identified who fulfilled the criteria for this study. The follow-up period ranged from 13 to 113 months (median 68 months).

Totally, 24 patients $(63.2 \%)$ were males and the mean age in all patients was 53 years (range 21-85). Overall, 23 right eyes and 15 left eyes were treated.

The primary diagnosis included retinal detachment (RD) (17 patients), RD and proliferative vitreoretinopathy (PVR) grade $\mathrm{C}$ or greater (nine patients), RD secondary to trauma (seven patients), RD related to proliferative diabetic retinopathy (three patients), RD and macular hole (one patient) and RD due to giant retinal tear (one patient). The total number of vitreoretinal procedures patients underwent is shown in Figure 1, which demonstrates that overall 30 patients $(78.9 \%)$ had one or two vitreoretinal (VR) procedures. All patients whose IOP was not controlled at 1 year (10) and final follow-up (5) had had one or two previous VR procedures.

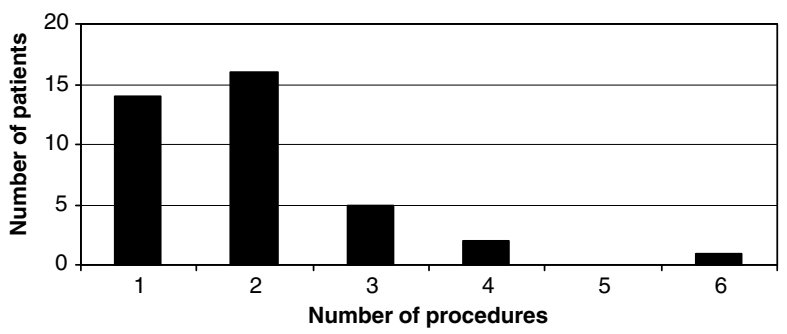

Figure 1 Number of vitreoretinal procedures.
At the time of first cyclodiode treatment, four (10.5\%) patients were phakic, $16(42.1 \%)$ patients were pseudophakic and $18(47.4 \%)$ patients were aphakic. In total five patients had had a retinectomy: in two this extended to $90^{\circ}$ and the remaining three it was between 90 and $270^{\circ}$. At the time of first cyclodiode 17 patients $(44.7 \%)$ had silicone oil in situ. There was previous history of glaucoma in four patients (10.5\%).

Cyclodiode laser was performed at a power of 1.5-2.0 W, for a duration of 1.5-2.0 s and with 20-60 applications. Overall, 18 patients $(47.4 \%)$ required only one cyclodiode treatment and the remaining patients received up to four treatments to control their raised IOP (Figure 2). There was no statistically significant correlation between the laser power and the success in IOP reduction in this group of patients.

Changes in IOP following cyclodiode, at 1 year and final follow-up are shown in Table 1. It shows that 28 patients $(73.8 \%)$ at 1 year and $33(86.8 \%)$ at their final visit had controlled IOP. Among those with uncontrolled IOP, seven out of 10 at 1 year and four out of five at last visit had IOPs of $30 \mathrm{mmHg}$ or less. The mean IOP was $18.6 \mathrm{mmHg}$ (SD 8.6) at 1 year and $13.9 \mathrm{mmHg}$ (SD 8.4) at the final visit compared to the pre-op mean value of $31.4 \mathrm{mmHg}$ (SD 10.9) $(P<0.001$, paired $t$-test). Hypotony (IOP of less than $5 \mathrm{mmHg}$ ) was found in four patients $(10.5 \%)$ at 1 year and in five patients $(13.2 \%)$ at the final follow-up one of whom was a trauma case who underwent enucleation 95 months after initial silicone

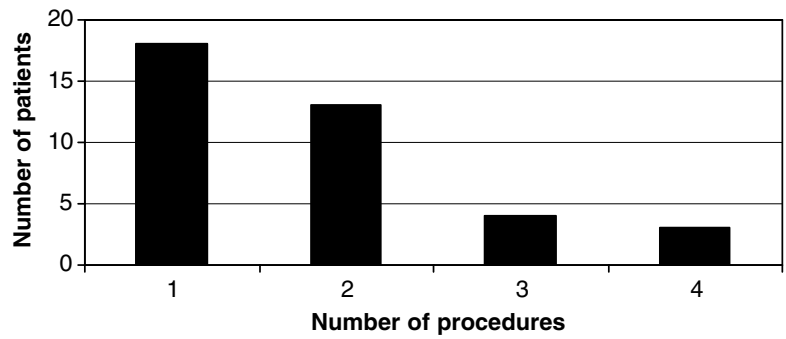

Figure 2 Number of cyclodiode procedures.

Table 1 IOP of the study eye, pretreatment, immediately posttreatment, and at 1 year and final visit

\begin{tabular}{lcccc}
\hline $\begin{array}{l}\text { IOP in } \\
\text { study eye }\end{array}$ & Pre-op $n$ & Post-op $n$ & One year $n$ & Final visit $n$ \\
\hline$\leqslant 21$ & 8 & 33 & 28 & 33 \\
$>21$ & 30 & 5 & 10 & 5 \\
$22-30$ & 11 & 4 & 7 & 4 \\
$31-40$ & 13 & 0 & 2 & 0 \\
$41-50$ & 5 & 0 & 1 & 1 \\
$51-60$ & 0 & 1 & 0 & 0 \\
64 & 1 & 0 & 0 & 0 \\
Mean IOP (SD) & $41.4(10.9)$ & $17.1(8.1)$ & $18.6(8.6)$ & $13.9(8.4)$ \\
\hline
\end{tabular}

$n=$ number of eyes. 
oil injection and 75 months after cyclodiode

treatment.The IOP at 1 year follow-up in this eye was $2 \mathrm{mmHg}$.

There were significant reductions in the numbers of patients using acetazolamide and topical hypertensive medications. In total, 28 patients were on two or more topical antihypertensive medications prior to their cyclodiode treatment. This was reduced to 18 patients at 1 year and 13 patients at the final follow-up visit (McNemar's $P=0.013$ and 0.0007 , respectively). With regard to the systemic medications, preoperatively 16 patients were taking oral acetazolamide, whereas at 1 year five patients were on oral acetazolamide and at the final visit only three patients required this systemic treatment (Table 2). (McNemar's $P=0.0034$ and 0.001, respectively).

The relation between the lens and the silicone oil status and the IOP at 1 year and at final follow-up is shown in Table 3. There were $18(47.5 \%)$ aphakic, $16(42.1 \%)$, and four $(10.5 \%)$ phakic patients at 1 year. These numbers did not change at the final follow-up.

At 1 year, 15 patients (39.5\%) had silicone oil in situ 12 of whom had normal IOP. The remaining three had IOPs of 22, 28, and $45 \mathrm{mmHg}$. By the final follow-up 13 (34.2\%) patients had silicone oil in situ with 10 of them having normal IOPs. The remaining three had IOPs of 22, 24, and $44 \mathrm{mmHg}$.

There was no correlation between the duration of silicone oil in situ and the final outcome of controlled IOP following cyclodiode treatment.

\section{Discussion}

Secondary IOP elevation after silicone oil injection has proved to be a challenging problem to control medically.
The incidence of silicone oil related glaucoma is reported to be between 5.9 and $48 \% .^{1-5}$ Known risk factors for silicone oil-induced raised IOP include pre-existing glaucoma, diabetes, and aphakia. ${ }^{2,3}$ The mechanism of silicone oil related glaucoma may be due to migration of emulsified oil to the anterior chamber and into the trabecular meshwork, synaechial angle closure, rubeosis iridis, pupillary block, and inflammation, or to a combination of these. Medical treatment aims at reducing the aqueous production and inflammatory response using aqueous suppressants and steroids as well as cycloplegics. Prophylactic surgical inferior iridectomy reduces the risk of pupillary block glaucoma.

Although there are reports of normalisation of IOP following silicone oil removal ${ }^{8}$ this issue remains controversial and several previous reports suggest that removal of silicone oil alone may be insufficient to alleviate the glaucoma. ${ }^{6,9-13}$ It is, however, generally accepted that where possible prompt removal of silicone oil will minimise its potential ocular side effects. This is not always desirable because of the risk of redetachment which has been reported in up to one in three patients ${ }^{9}$ particularly those with complex previous vitreoretinal pathology. ${ }^{14}$

Glaucoma surgery on these difficult cases is often unsuccessful due to pre-existing conjunctival scarring following vitreoretinal procedures. ${ }^{4}$ Glaucoma drainage implants offer an alternative surgical option but oil migration can occur through the tube into the subconjunctival space inciting an inflammatory reaction. ${ }^{15,16}$ Cyclodiode treatment can provide good IOP control as reported by Bloom et $a l^{17}$ and Han et al ${ }^{18}$ with success rates of 66 and $82 \%$ respectively. Our data indicate a long-term success rate of $74 \%$ at 1 year and

Table 2 Systemic medication pretreatment, 1 year and last visit

\begin{tabular}{|c|c|c|c|c|c|}
\hline & & \multicolumn{2}{|c|}{ One year } & \multicolumn{2}{|c|}{ Final visit } \\
\hline & & No acetazolamide & Acetazolamide & No acetazolamide & Acetazolamide \\
\hline \multirow[t]{3}{*}{ Pre-op } & No acetazolamide & 21 & 1 & 21 & 1 \\
\hline & Acetazolamide & 12 & 4 & 14 & 2 \\
\hline & $P$-value (McNemar's) & 0.0034 & & 0.001 & \\
\hline
\end{tabular}

Table 3 Lens and silicone oil status at 1 year and final follow-up

\begin{tabular}{|c|c|c|c|c|c|c|c|c|}
\hline \multirow[t]{2}{*}{$I O P$} & \multicolumn{4}{|c|}{ One year } & \multicolumn{4}{|c|}{ Final visit } \\
\hline & Aphakic & Pseudophakic & Phakic & Oil in situ & Aphakic & Pseudophakic & Phakic & Oil in situ \\
\hline$<22 \mathrm{mmHg}$ & 13 & 11 & 4 & 12 & 15 & 15 & 3 & 10 \\
\hline$>22 \mathrm{mmHg}$ & 5 & 5 & 0 & 3 & 3 & 1 & 1 & 3 \\
\hline
\end{tabular}


$86 \%$ at final follow-up of up to 113 months (median 68 months). Notably, our overall results show that of the five cases which had 'uncontrolled' IOP at final visit four had IOP of $30 \mathrm{mmHg}$ or less. This may represent an adequate level of IOP control in eyes with complex multiple pathologies (and a poor visual prognosis). To our knowledge these are the longest follow-up data reported on silicone oil-related glaucoma patients.

In the present study, 17 patients $(45 \%)$ had silicone oil in situ at the time of first cyclodiode treatment, 15 (39.5\%) patients had oil in situ at 1 year and 13 (34\%) patients at the final follow-up visit. At 1 year and final follow-up visits only three patients with oil in situ had IOPs greater than $21 \mathrm{mmHg}$ of whom two had IOPs of less than $30 \mathrm{mmHg}$. Removal of silicone oil was performed in three patients following cyclodiode (two patients within the first year of treatment). Our long-term-follow up results (of up to 113 months) are similar to those in a previous report by Han et $a l^{18}$ where good IOP control was achieved with the silicone oil in situ up to 68 weeks after diode laser photocoagulation. Overall, these findings suggest that initial IOP control in these eyes is maintained long term.

Systemic antiglaucoma medication was necessary in only $13 \%$ of patients at 1 year and $8 \%$ at the final followup compared to $42 \%$ prior to cyclodiode. In addition to IOP control, cyclodiode treatment has an important role in reducing the need for the long-term use of systemic medication and the inevitable side-effects associated with this.

Chronic hypotony is a common problem following cyclodestructive procedures. Cyclodiode treatment does however carry a lower incidence of complications compared to cyclocryotherapy. Suzuki et al ${ }^{19}$ compared 36 eyes which had undergone cyclodiode with 80 eyes treated with cyclocryo. Three patients in the cyclodiode group (8\%) had complications one of whom had hypotony whereas the rate of complication in the cyclocryo-treated group was 30\% (24 patients, two with hypotony). ${ }^{19}$ Schuman $\mathrm{et} \mathrm{al}^{20}$ reported a $10 \%$ incidence of hypotony and phthisis after $\mathrm{Nd}$ :Yag

cyclophotocoagulation, which is similar to the $10.5 \%$ hypotony rate (including one case of enucleation) at the final follow-up (5\% at 1 year) in this study. All patients in our study with hypotony had the silicone oil in situ at the final follow-up.

Cyclodiode treatment has the advantage of being repeatable if required and $52 \%$ of the patients in this study had more than one treatment session. In our study group, nearly $20 \%$ of patients had more than two VR procedures, however, none of these had uncontrolled IOP at 1 year or at final follow-up visit. The long-term effect of cyclodiode treatment in lowering IOP in a controlled manner in silicone oil-related glaucoma is encouraging and this treatment modality should be considered as an effective method of treatment in these often challenging eyes. It would seem reasonable to consider such treatment at an early stage in the management of these cases.

\section{References}

1 Barr CC, Lai MY, Lean JS, Linton KL, Trese M, Abrams G et al. Postoperative intraocular pressure abnormalities in the Silicone Study. Silicone Study Report 4. Ophthalmology 1993; 100: $1629-1635$.

2 Henderer JD, Budenz DL, Flynn Jr HW, Schiffman JC, Feuer WJ, Murray TG. Elevated intraocular pressure and hypotony following silicone oil retinal tamponade for complex retinal detachment: incidence and risk factors. Arch Ophthalmol 1999; 117: 189-195.

3 Honavar SG, Goyal M, Majji AB, Sen PK, Naduvilath T, Dandona L. Glaucoma after pars plana vitrectomy and silicone oil injection for complicated retinal detachments. Ophthalmology 1999; 106: 169-176.

4 Nguyen QH, Lloyd MA, Heuer DK, Baerveldt G, Minckler $\mathrm{DS}$, Lean JS et al. Incidence and management of glaucoma after intravitreal silicone oil injection for complicated retinal detachments. Ophthalmology 1992; 99: 1520-1526.

5 Valone Jr J, McCarthy M. Emulsified anterior chamber silicone oil and glaucoma. Ophthalmology 1994; 101: 1908-1912.

6 Moisseiev J, Barak A, Manaim T, Treister G. Removal of silicone oil in the management of glaucoma in eyes with emulsified silicone. Retina 1993; 13: 290-295.

7 Scott JD In: Surgery for Retinal and Vitreous Disease. Butterworth Heinmann: Oxford, 1998 pp 339-342.

8 Jonas JB, Knorr HL, Rank RM, Budde WM. Intraocular pressure and silicone oil endotamponade. J Glaucoma 2001; 10: $102-108$

9 Casswell AG, Gregor ZJ. Silicone oil removal. I. The effect on the complications of silicone oil. Br J Ophthalmol 1987; 71: 893-897.

10 Casswell AG, Gregor ZJ. Silicone oil removal. II. Operative and postoperative complications. Br J Ophthalmol 1987; 71: 898-902.

11 Federman JL, Schubert HD. Complications associated with the use of silicone oil in 150 eyes after retina-vitreous surgery. Ophthalmology 1988; 95: 870-876.

12 Franks WA, Leaver PK. Removal of silicone oil-rewards and penalties. Eye 1991; 5 (Part 3): 333-337.

13 Leaver PK, Billington BM. Vitrectomy and fluid/silicone-oil exchange for giant retinal tears: 5 years follow-up. Graefes Arch Clin Exp Ophthalmol 1989; 227: 323-327.

14 Pearson RV, McLeod D, Gregor ZJ. Removal of silicone oil following diabetic vitrectomy. Br J Ophthalmol 1993; 77: 204-207.

15 Hyung SM, Min JP. Subconjunctival silicone oil drainage through the Molteno implant. Korean J Ophthalmol 1998; 12: 73-75.

16 Senn P, Buchi ER, Daicker B, Schipper I. Bubbles in the bleb - troubles in the bleb? Molteno implant and intraocular tamponade with silicone oil in an aphakic patient. Ophthalmic Surg 1994; 25: 379-382.

17 Bloom PA, Tsai JC, Sharma K, Miller MH, Rice NS, Hitchings RA et al. 'Cyclodiode'. Trans-scleral diode laser 
cyclophotocoagulation in the treatment of advanced refractory glaucoma. Ophthalmology 1997; 104: 1508-1519.

18 Han SK, Park KH, Kim DM, Chang BL. Effect of diode laser trans-scleral cyclophotocoagulation in the management of glaucoma after intravitreal silicone oil injection for complicated retinal detachments. Br J Ophthalmol 1999; 83: 713-717.
19 Suzuki Y, Araie M, Yumita A, Yamamoto T. Transscleral Nd: YAG laser cyclophotocoagulation versus cyclocryotherapy. Graefes Arch Clin Exp Ophthalmol 1991; 229: 33-36.

20 Schuman JS, Bellows AR, Shingleton BJ, Latina MA, Allingham RR, Belcher CD et al. Contact transscleral Nd:YAG laser cyclophotocoagulation. Midterm results. Ophthalmology 1992; 99: 1089-1094. 